\section{Fenofibrate-induced rhabdomyolysis in a patient with chronic kidney disease: an unusual presenting feature of hypothyroidism}

\author{
Rabdomiólise induzida por fenofibrato em paciente com doença renal \\ crônica: uma apresentação clínica incomum do hipotireoidismo
}

Alessandra Alves de Sousa' ${ }^{1}$, Hans Stauber Kronit' ${ }^{1}$, Francisco de Assis Rocha Neves ${ }^{2}$, Angélica Amorim Amato²
1 Sociedade de Clínica Médica (Soclimed), Unidade de Nefrologia e Hemodiálise, Brasília, Brazil 2 Soclimed, Unidade de Nefrologia e Hemodiálise, Brasília, Brazil; Laboratório de Farmacologia Molecular, Departamento Farmácia, Faculdade de Ciências da Saúde, Universidade de Brasília (UnB), Brasília, Brazil

Correspondence to: Angélica Amorim Amato Faculdade de Ciências Médicas, UnB

Caixa Postal 04473

70919-970 - Brasília, DF, Brasil

angelicamato@hotmail.com

Received in Jan/6/2009

Accepted in Feb/23/2009

\section{INTRODUCTION}

$\mathrm{M}$ usculoskeletal symptoms in adults with hypothyroidism are frequent ( 1 ) and can be the first sign of thyroid dysfunction $(2,3)$. Hypothyroid myopathy is usually limited to asymptomatic elevation of serum creatinine phosphokinase (CPK) concentration, myalgias, muscle stiffness, delayed relaxation of tendon reflexes, cramps and proximal muscle weakness $(4,5)$. Prominent changes, such as acute myoedema, Hoffman's syndrome and rhabdomyolysis, have otherwise only been rarely reported $(4,6-8)$.

Rhabdomyolysis is a syndrome involving skeletal muscle necrosis and the consequent release of intracellular muscle proteins and electrolytes into the systemic circulation. Its severity is variable, ranging from asymptomatic elevations in serum muscle enzymes levels to life-threatening electrolyte disturbances and acute renal failure (9). The development of rhabdomyolysis is as- 
sociated with a number of different conditions, such as infections, trauma, strenuous physical exertion, drugs, toxins, electrolyte abnormalities, heritable muscle enzyme deficiencies, and endocrinopathies, although in many cases the precise etiology is not readily identified $(10,11)$. The typical clinical presentation includes muscle weakness, myalgias and dark-colored urine due to myoglobinuria, and the diagnosis is usually established by elevated serum skeletal muscle enzyme levels (12). CPK is the most sensitive indicator of muscle injury and, although there is no defined serum cut-off level for the diagnosis, many clinicians use five to ten times the upper limit of normal range (13). The mainstay of treatment is aggressive intravenous fluid administration and correction of electrolyte abnormalities, and the cause of rhabdomyolysis should always be specifically treated when identified $(9,13)$. Additional measures include urinary alkalinization and diuretic therapy when euvolemia has been achieved but, because of the lack of randomized controlled trials to investigate the effectiveness of these adjunct therapies, their use remains of unproven benefit (13). With early and vigorous hydration and other measures to preserve renal function, the overall prognosis for rhabdomyolysis is good (13).

We reported a patient with chronic kidney disease who presented with rhabdomyolysis during fenofibrate therapy for hypertriglyceridemia, and was subsequently found to have hypothyroidism.

\section{CASE REPORT}

A 54-year-old white man was admitted because of increasing myalgias and coluria.

His past medical history was remarkable for stage 3 chronic kidney disease secondary to polycystic kidney disease, which was diagnosed seven years before and managed expectantly, and also for arterial hypertension and hypertriglyceridemia. He was being treated with nifedipine OROS $30 \mathrm{mg}$ bid and propranolol $40 \mathrm{mg}$ bid. Micronized fenofibrate (200 mg q.d.) was added in the last two months, because of persistent hypertriglyceridemia despite nonpharmacologic measures. The patient had been relatively stable until three months before admission, when he insidiously developed fatigue, dry and pale skin, coarseness of his voice, maleolar edema and loss of body hair (predominantly in the legs). Five days before admission, he began to have odynophagia, dry cough, headache and malaise, and was evaluated in the emergency department. Acute sinusitis was diagnosed, azithromicyn and nimesulide were started, but all symptoms persisted. Three days days before admission, the patient developed myalgias, which were most severe in the proximal muscles of his upper extremities, and also noticed coluria. He reported exercising regularly (30-minute brisk walk, three times a week), but denied any form of moderate to strenuous physical activity. He reported family history of hypothyroidism due to Hashimoto's thyroiditis and type 1 diabetes mellitus.

On physical examination, the patient appeared pale, had periorbital puffiness, dryness and coarseness of the skin, loss of the lateral aspects of his eyebrows, hair loss in the distal part of his lower extremities, and a multinodular goiter. Heart rate was normal ( 72 beats $/ \mathrm{min}$.), muscle strength was $3 / 5$, and relaxation of deep tendon reflexes was delayed. No other abnormalities were detected on physical examination.

Initial laboratory tests revealed normocytic-normochromic anemia (hematocrit: $32,7 \%$, reference range: 37,8-48,6), glucose $78 \mathrm{mg} / \mathrm{dL}$ (reference range: 70-99), $\mathrm{Na} 137 \mathrm{mEq} / \mathrm{L}$ (reference range: 135-150), K 6,3 $\mathrm{mEq} / \mathrm{L}$ (reference range: 3,5-5,0), albumin $3,7 \mathrm{~g} / \mathrm{dL}$ (reference range: $3,4-4,8$ ) and increased creatinine levels $(4,9 \mathrm{mg} / \mathrm{dL}$, reference range: $0,7-1,2)$. Serum muscle enzyme levels were markedly elevated: CPK 52.749 IU/L (reference range: 39-308), lactic dehydrogenase $1.444 \mathrm{IU} / \mathrm{L}$ (reference range: 100-190) and aspartate aminotransferase $200 \mathrm{IU} / \mathrm{L}$ (reference range: < 37). His baseline creatinine level (measured four months before admission) was $2,54 \mathrm{mg} / \mathrm{dL}$, and a lipid profile obtained two months earlier showed total cholesterol $204 \mathrm{mg} / \mathrm{dL}$ (reference range: < 200), LDL-cholesterol 107 (reference range: < 100), HDL-cholesterol 36 (reference range: $>40$ ) and triglyceride 304 (reference range: $<150$ ). Other laboratory values are shown in table 1.

Urinary analysis disclosed $3+$ proteinuria and $2+$ hematuria with dipstick, 16 red cells per high-power field and no pigmented casts. Thyroid-stimulating hormone (TSH) serum concentration was $86,5 \mathrm{mcUI} / \mathrm{mL}$ (reference range: $0,4-4,0$ ), free thyroxin levels were $<0,2 \mathrm{pmol} / \mathrm{L}$ (reference range: $0,75-1,85$ ) and triiodothyronine levels were $<40 \mathrm{ng} / \mathrm{dL}$ (reference range: 60-200). Thyroid peroxidase antibody titer was strongly positive $(2.135 \mathrm{IU} / \mathrm{L})$, and thyroid ultrassonography revealed a diffusely heterogeneous gland with three hyperechogenic and two cystic nodules at the right lobe ( 3 to $7 \mathrm{~mm}$ ), and a hyperechogenic nodule with cystic areas at the left lobe $(22 \mathrm{~mm})$. 
Table 1. Blood chemical values during hospital stay

\begin{tabular}{|c|c|c|c|c|c|c|c|}
\hline \multirow{2}{*}{ Variable } & \multicolumn{7}{|c|}{ Hospital day } \\
\hline & $1^{\text {st }}$ & $3^{\text {rd }}$ & $5^{\text {th }}$ & $7^{\text {th }}$ & $9^{\text {th }}$ & $11^{\text {th }}$ & Reference range \\
\hline CPK (IU/L) & 52.749 & 31.000 & 14.400 & 3.591 & 1.890 & 755 & $39-308$ \\
\hline Lactic dehydrogenase (IU/L) & 1.444 & 1.760 & 2.020 & 1.514 & 1.362 & & $100-190$ \\
\hline Aspartate aminotransferase (IU/L) & 200 & 1,750 & 1.230 & 512 & 268 & 162 & $<37$ \\
\hline Urea (mg/dL) & 121 & 103 & 103 & 89 & 84 & 79 & $10-50$ \\
\hline Creatinine (mg/dL) & 4,9 & 4,7 & 5,0 & 3,9 & 3,8 & 3,4 & $0,7-1,2$ \\
\hline
\end{tabular}

Note: on the first hospital day, after the results of initial laboratory tests were obtained, fenofibrate and propranolol were discontinued, and the patient was carefully treated with intravenous fluids, urinary alkalinization and levothyroxine.

Fenofibrate and propranolol were discontinued on admission, and the patient was carefully treated with intravenous fluids, urinary alkalinization and levothyroxine. He had progressive improvement of symptoms and muscle strength, and the serum concentration CPK gradually decreased. Renal function improved but did not return to baseline levels (Table 1 ).

\section{DISCUSSION}

The present report described a patient with chronic kidney disease and undiagnosed primary hypothyroidism, who presented with rhabdomyolysis while taking fenofibrate for the treatment of hypertriglyceridemia.

Hypothyroid myopathy includes a wide clinical spectrum, and is frequently correlated to the duration and biochemical severity of hypothyroidism $(6,7)$. Overt rhabdomyolysis, even in the most severe cases of thyroid dysfunction, is rarely precipitated by hypothyroidism alone (14-16). Most cases described to date have been associated with an additional factor of muscle injury, such as strenuous physical activity (17), infection, trauma (18), lipid-lowering agents (19), alcohol or other toxic agents, or with previous unrecognized congenital deficiency of muscle enzymes (4) or chronic kidney disease $(4,8,20,21)$.

The precise pathophysiology of rhabdomyolysis in hypothyroidism is currently not clear (22). Skeletal muscle cell metabolic abnormalities are currently believed to be the basis of hypothyroid myopathy, in particular mitochondrial dysfunction. Thyroid hormone has been shown to regulate the expression of genes encoding structural and regulatory proteins involved in mitochondrial respiratory function (23), and their expression has been found to be reduced in skeletal muscle of hypothyroid patients (24). Because the deficiency of these proteins has been implicated in some primary mi- tochondrial disorders with musculoskeletal involvement (25), it could also be a possible mechanism underlying hypothyroid myopathy. Muscle involvement in hypothyroidism is characterized by decreased concentration of fast twitching type II fibers and increased concentration of slow twitching type I fibers, low myosin ATPase activity, and low ATP turn-over in skeletal muscle (8). Hypothyroidism is also associated with impairment of mitochondrial oxidative metabolism and many other metabolic pathways, such as Krebs cycle, fatty acid catabolism and glycolytic energy production $(5,7,26)$. These metabolic abnormalities might sensitize muscle cells to other factors related to muscle injury and increase the risk of rhabdomyolysis $(6,7,27)$.

It has been also suggested that an autoimmune mechanism could play a role (27). However, the histological findings of fiber necrosis in the absence of an inflammatory infiltrate suggest that an autoimmune basis is unlikely (20).

The diagnosis of rhabdomyolysis in this patient was established on the basis of myalgia, muscle weakness, prominent elevation of serum levels of CPK, lactate dehydrogenase, aspartate aminotransferase and also creatinine. Nevertheless, the cause of rhabdomyolysis cannot be precisely defined. Since fenofibrate monotherapy-induced rhabdomyolysis is extremely rare and most of the cases described so far have been associated with an additional factor of muscle injury (28), it seems reasonable to speculate that both therapy with fenofibrate and undiagnosed hypothyroidism were involved, and also that chronic kidney disease might have had a contributory role.

Hypothyroidism represents a rare but definite cause of rhabdomyolysis, and should always be suspected in patients presenting with muscle aches and high serum concentrations of muscle enzymes - even in the presence of other determinants of muscle injury $(20,27,29,30)$. As pre- 
sented in this report and by others $(7,31)$, the association of lipid-lowering agents and hypothyroidism as a cause of rhabdomyolysis suggests the need for evaluation of thyroid function when therapy with fibric acid derivatives or statins is considered, especially in patients with chronic kidney disease $(32,33)$. Assessment of thyroid status is also recommended when patients on lipid-lowering agents develop myophatic symptoms or resistance to therapy (26). Not only hypothyroidism is an established secondary cause of dyslipidemia, but it might also potentiate the risk of myopathy induced by lipid-lowering agents (34-37).

Disclosure: no potential conflict of interest relevant to this article was reported.

This work did not receive any specific grant from any funding agency in the public, commercial or not-for-profit sector.

\section{REFERENCES}

1. Cakir M, Samanci N, Balci N, Balci MK. Musculoskeletal manifestations in patients with thyroid disease. Clin Endocrinol. 2003;59(2):162-7.

2. White $\mathrm{GH}$, Walmsley RN. Plasma enzyme activities in primary hypothyroidism. Clin Chem. 1984;30(2):323-5.

3. Benvenga S, Toscano A, Rodolico C, Vita G, Trimarchi F. Endocrine evaluation for muscle pain. J R Soc Med. 2001;94(8):405-7.

4. Sekine N, Yamamoto M, Michikawa M, Enomoto T, Hayashi M, Ozawa $\mathrm{E}$, et al. Rhabdomyolysis and acute renal failure in a patient with hypothyrodism. Int Med. 1993;32(3):269-71.

5. Soltani P, Rezvanfar MR, Pirasteh S. Acute renal failure in a patient with Sheehan Syndrome and rhabdomyolysis. IJKD. 2008;2(1):50-2.

6. Miller ML, Rubin DI. Hypothyroid myopathy. UpToDate [serial on the Internet]. 2007 Dec [cited 2009 Jan 5]. Available from: http:// www.uptodate.com/online/content/topic.do?topicKey=medneur o/8565\&selectedTitle=1 3\&source=search_result

7. Clouâtre Y, Leblane M, Ouimet D, Pichette V. Fenofibrate-induced rhabdomyolysis in two dialysis patients with hypothyroidism. Nephrol Dial Transplantat. 1999;14(4):1047-8.

8. Bhansali A, Chandran V, Ramesh J, Kashyap A, Dash RJ. Acute myoedema: an unusual presenting manifestation of hypothyroid myopathy. Postgrad Med J. 2000;76(892):99-100.

9. Huerta-Alardin AL, Varon J, Marik PE. Bench-to-bedside review: rhabdomyolysis--an overview for clinicians. Crit Care. 2005;9(2):158-69.

10. Warren JD, Blumbergs PC, Thompson PD. Rhabdomyolysis: a review. Muscle Nerve. 2002;25(3):332-47.

11. Polderman $\mathrm{KH}$. Acute renal failure and rhabdomyolysis. Int J Artif Organs. 2004;27(12):1030-3.

12. Sauret J, Marinides G, Wang G. Rhabdomyolysis. Am Fam Phys. 2002;65(5):907-12.

13. Bagley WH, Yang H, Shah KH. Rhabdomyolysis. Intern Emerg Med. 2007;2(3):210-8.

14. Freeston J, Gough A. Reversible myopathy and renal impairment. J R Soc Med. 2004;97(3):124-5.

15. Mazokipakis EE. Unusual causes of rhabdomyolysis. Intern Med J. 2008;38(5):364-7.

16. Galli-Tsinopoulou A, Stylianou C, Kokka P, Panagopoulou P, Nousia-Arvanitakis $\mathrm{S}$. Rhabdomyolysis, renal failure, pericardial effusion, and acquired von Willebrand disease resulting from hypothyroidism in a 10-year-old girl. Thyroid. 2008;18(3):373-5.

17. Nelson SR, Phillips AO, Hendry BM. Hypothyroidism and rhabdomyolysis in a marathon runner. Nephrol Dial Transplant. 1993;8(4):375-6.

18. Vold PL, Weiss PJ. Rhabdomyolysis from tourniquet trauma in a patient with hypothyroidism. West J of Med. 1995;162(3):270-2.

19. Satarasinghe RL, Ramesh R, Riyaaz AA, Gunarathne PA, de Silva AP. Hypothyroidism is a predisposing factor for fenofibrate-induced rhabdomyolysis--patient report and literature review. Drug Metabol and Drug Interact. 2007;22(4):279-83.

20. Kisakol G, Tunc R, Kaya A. Rhabdomyolysis in a patient with hypothyroidism. Endocr J. 2003;50(2):221-3.

21. Grahan DJ, Staffa JA, Shatin D, Andrade SE, Schech SD, La Grenade LL, et al. Incidence of hospitalized rhabdomyolysis in patients treated with lipid-lowering drugs. JAMA. 2004;292(21):2585-90.

22. Rabhi M, Chaari J, Toloune F. Rhabdomyolysis disclosing hypothyroidism. Eur J Int Med. 2006;17(3):220.

23. Argov Z, Renshaw PF, Boden B, Winkokur A, Bank WJ. Effects of thyroid hormones on skeletal muscle bioenergetics. In vivo phosphorus-31 magnetic resonance spectroscopy study of humans and rats. J Clin Invest. 1988;81(6):1695-701.

24. Siciliano G, Monzani F, Manca ML, Tessa A, Caraccio N, Tozzi G, et al. Human mitochondrial transcription factor $A$ reduction and $\mathrm{mi}-$ tochondrial dysfunction in Hashimoto's hypothyroid myopathy. Mol Med. 2002;8(6):326-33.

25. Larsson NG, Wang J, Wilhelmsson H, Oldfors A, Rustin P, Lewandoski $\mathrm{M}$, et al. Mitochondrial transcription factor $\mathrm{A}$ is necessary for mtDNA maintenance and embryogenesis in mice. Nat Genet. 1998;18(3):231-36

26. Bar SL, Holmes DT, Frohlich J. Asymptomatic hypothyroidism and statin-induced myopathy. Can Fam Physician. 2007;53(3):428-31.

27. Barahona MJ, Mauri A, Sucunza N, Paredes R, Wägner AM. Hypothyroidism as a cause of rhabdomyolysis. Endocr J. 2002;49(6):621-3.

28. Tahmaz M, Kumbasar B, Ergen K, Ure U, Karatemiz G, Kazancioglu R. Acute renal failure secondary to fenofibrato monotherapyinduced rhabdomyolysis. Ren Fail. 2007;29(8):927-30.

29. Altay M, Duranay M, Ceri M. Rhabdomyolysis due to hypothyroidism. Nephrol DialTransplant. 2005;20(4):847-8.

30. Birewar S, Oppenheimer M, Zawada ET. Hypothyroid acute renal failure. S D J Med. 2004;57(3):109-10.

31. Qari FA. Severe rhabdomyolysis and acute renal failure secondary to use of simvastatin in undiagnosed hypothyroidism. Saudi J Kidney Dis Transplant. 2009;20(1):127-9.

32. Kiernan TJ, Rochford M, McDermott JH. Simvastatin induced rhabdomyolysis and an important clinical link with hypothyroidism. Int J Cardiol. 2007;119(3):374-6.

33. Yeter E, Keles T, DurmazT, Bozkurt E. Rhabdomyolysis due to the additive effect of statin therapy and hypothyroidism: a case report. J Med Case Reports. 2007;1:130.

34. Al-Jubouri MA, Briston PG, Sinclair D, Chinn RH, Young RM. Lesson of the week: myxoedema revealed by simvastatin induced myopathy. BMJ. 1994;308(6928):588.

35. Tokinaga K, Oeda T, Suzuki Y, Matsushima Y. HMG-CoA reductase inhibitors (statins) might cause high elevations of creatinine phosphokinase (CK) in patients with unnoticed hypothyroidism. Endocr J. 2006;53(3):401-5.

36. Olukoga AO, Crowley VEF, Lawal A, Weinkove C. Hyperlipidaemia and hypothyroidism. Screen patients for hypothyroidism before treatment. BMJ. 1994;308(6933):918.

37. Kisch E, Segall HS. Interaction between simvastatin and L-thyroxin. Ann Int Med. 2005;143(7):547. 